\title{
Metodologias contemporâneas do ensino do teatro em foco, a sala de aula
}

\author{
Arão N. Paranaguá de Santana
}

\section{SciELO Books / SciELO Livros / SciELO Libros}

SANTANA, A.N.P. Metodologias contemporâneas do ensino do teatro: em foco, a sala de aula. In: FLORENTINO, A., and TELLES, N., eds. Cartografias do ensino do teatro [online]. Uberlândia: EDUFU, 2008, pp. 29-35. ISBN 978-85-7078-518-3. https://doi.org/10.7476/9788570785183.0004.

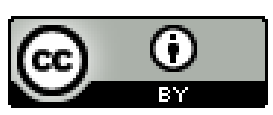

All the contents of this work, except where otherwise noted, is licensed under a Creative Commons Attribution 4.0 International license.

Todo o conteúdo deste trabalho, exceto quando houver ressalva, é publicado sob a licença Creative Commons Atribição $\underline{4.0}$.

Todo el contenido de esta obra, excepto donde se indique lo contrario, está bajo licencia de la licencia $\underline{\text { Creative Commons }}$ Reconocimento 4.0. 


\section{METODOLOGIAS CONTEMPORÂNEAS DO ENSINO DE TEATRO: EM FOCO A SALA DE AULA}

Arão N. Paranaguá de Santana

Na virada do milênio, as concepções culturais emergentes germinaram no campo da educação valores como respeito ao receptor, intertextualidade, fragmentação de um discurso anteriormente linear, pluralismo, utilização de meios tecnológicos inovadores, dentre outros fenômenos que vislumbram, a um só tempo, ruptura e crise, face ao convívio com procedimentos desgastados, embora recorrentes - didáticas autoritárias, práticas repetitivas, o novo que se acha belo porque desconhece memória e tradição.

Perplexidades como essas têm motivado o debate em encontros de especialistas, pesquisas e publicações, fazendo-se presente, sobretudo no trabalho cotidiano dos docentes. Nesse esteio surgem estudos consubstanciados na nova sociologia da educação, na psicopedagogia, na teoria crítica, na pedagogia dos conteúdos, no multiculturalismo e noutras vertentes que compõem o imenso arquipélago da teoria social da atualidade.

Esses trabalhos têm contribuído para o avanço de propostas teóricas e metodológicas relativas ao ensino e ao aprendizado, possibilitando aos educadores certo distanciamento para que possam relativizar as diferenças entre os estágios de desenvolvimento material e cultural dos alunos, concedendo-lhes, também, as estratégias para compreensão dos percursos de entrada e saída numa modernidade alcançada apenas por pequena parcela da população mundial ${ }^{1}$.

Em face desses fenômenos estampados no tecido social e suas implicações na escolarização, creio que o ensino de Arte, ou pelo menos uma parcela significativa de seus praticantes, tem procurado fundamentar-se em obras e conceitos revelados na arte contemporânea, no fazer dos artistas, no pensar dos críticos, nas práticas culturais comunitárias, nas propostas de museus e instituições culturais, sem ignorar, contudo, a realidade da sala de aula. Creio, também, que essa jornada ruma para a superação do fazer que caracterizou o sentido da formação em arte predominante durante séculos, bem como do sentir enquanto esfera da liberdade expressiva de fundo psicológico que alude à imanência estética, mas que, na verdade, não penetra na essência da arte, retomando a questão da reflexão como estatuto de um pensar que existe para tecer conexões entre esses três componentes da ação artística e pedagógica - fazer, sentir, pensar.

${ }^{1}$ Canclini, N. G. Culturas híbridas: estratégias para entrar e sair da modernidade. São Paulo: EDUSP, 1998. p. 17-30. 
Com o objetivo de contextualizar essa argumentação perante às indagações deste VI Seminário de Linguagens Artísticas, sou levado a guiar-me a partir de alguns pontos: i) em que bases metodológicas constituiu-se a área de Teatro-Educação? ii) como adaptar as proposições mais interessantes à realidade da sala de aula? iii) qual o perfil e o que pensam os professores, já que são eles os responsáveis diretos pela produção de conhecimentos e práticas escolares?

Considerando o quadro complexo que se apresenta para a compreensão de questões tão abertas, tentarei verificar, a partir de uma perspectiva histórica, se no caso das didáticas do Teatro é possível - ou não - assumir um discurso vanguardista, como nas Artes Visuais, por exemplo, campo onde florescem metodologias pós-modernas.

\section{Significados do teatro na escolarização}

Desde Aristóteles, tem-se pensado muito sobre o potencial reflexivo que permeia o fazer e o fruir, o pensar e o sentir contidos na arte dramática. A palavra drama vem de dromenon, referindo-se à ação, ao passo que teatro, vocábulo que também veio do grego, significa lugar donde se vê. Essa capacidade de ver-se em ação, criticando e apreciando os próprios gestos e atitudes, constituiu-se num recurso vital para o processo de humanização da natureza e, sendo inerente à atividade artística, tem implicações ontológicas no campo da educação.

Os nexos epistemológicos originários do Teatro-Educação remontam a um passado longínquo, embora sua vertente no ensino formal tenha sido consolidada somente nesse século, em resposta às necessidades do teatro moderno e aos reclames da sociedade em prol de uma consciência cidadã plenamente democrática.

Assim, no âmago de sua própria historicidade, criou-se uma cultura compreendendo os fins do Teatro na escolarização, suas metas pedagógicas e estéticas, conteúdos, atividades facilitadoras do aprendizado e procedimentos de avaliação. Ao longo desse processo de tornar-se disciplina foram sendo configurados métodos e teorias, visando-se superar os obstáculos suscitados através da ação.

Não consigo pensar em desenvolvimento curricular sem visualizar a imagem dos sujeitos que, na prática, são os deflagradores do processo de ensino e, como motivadores do aprendizado, escolhem os caminhos da ação pedagógica.

Para Gisèle Barret, o especialista em Teatro-Educação é um personagem estranho entre-deux, considerando-se a ambigüidade de sua atuação no limiar do teatro e da educação. A autora entende que essa área carece de definições no âmbito dos fundamentos, apesar de sua história importante no cenário acadêmico e escolar, propondo as seguintes reflexões:

Somos generalistas, especialistas, generalistas-especialistas ou especialistas-generalistas? Nós jogamos ou criamos arte? Fazemos teatro, teatro na educação, teatro improvisacional ou educação através do teatro? Usamos arte, ensinamos arte ou fazemos arte? ${ }^{2}$

\footnotetext{
2 BARRET, G. Le spécialiste en théâtre éducation: une personnage étrange entre-deux. IDEA Journal: Polyphonic voices, rainbow worlds: one destiny, v. 1, n. 1, p. 6, 1997. Tradução livre do autor em parceria com Ulisses Ferraz de Oliveira.
} 
Acirrando esse debate, Charles Combs observa que para realizar bem sua função o especialista em ensino de Teatro estabelece metas, objetivos e procedimentos, atribuindo, porém, propósitos bem mais específicos para sua conduta:

Nós queremos que o estudante aprenda, transforme-se e busque desenvolver-se; nós ensinamos, agimos, encenamos, criamos performances cotidianamente e interferimos mediando ações dentro das escolas, em contextos formais ou informais; usamos métodos de ensino, formas artísticas e valores culturais no nosso trabalho; trabalhamos como artistas, professores e mediadores - nós desejamos que o estudante ou pessoa continue a aprender e a desenvolver-se através da vida sem a nossa intervenção ${ }^{3}$.

Citei os pontos de vista desses dois especialistas internacionais com a intenção de atualizar o debate sobre os alicerces do Teatro-Educação e, assim, compreender melhor o perfil atribuído aos docentes, alimentando a reflexão acerca de um dilema sempre recorrente - estar entre dois. Para a superação desse entrave, Combs estabelece conexões entre quem e onde são produzidas as teorias e as propostas didáticas, assegurando que há uma fusão entre o que as lideranças intelectuais realizam e a ação das instituições; como corolário dessa argumentação, cita exemplos de parcerias que se revestiram de sucesso acadêmico em seu país ${ }^{4}$.

No caso brasileiro, pode ser comprovada uma situação semelhante, considerando-se a atuação decisiva de algumas universidades na pós-graduação, de seus professores na pesquisa e publicação de livros, além dos personagens pioneiros e outros mestres do presente que, com sua ação, vêm dando notoriedade ao ensino de Teatro ${ }^{5}$.

\section{Breve historiografia da didática do teatro na realidade escolar brasileira}

Até aqui busquei situar a disciplina Teatro frente ao estado atual da cultura, como pano de fundo para entender sua prática escolar numa época "de tecnologia avançada, iluminismo científico e iluminação estética", ao tempo em que propus uma reflexão sobre algumas questões pontuais. Tentarei agora discutir a insurgência dos métodos a partir de contribuições historicamente situadas, dando ênfase às influências absorvidas pela educação brasileira.

${ }^{3}$ ComBs, C. E. The drama/theatre/artist/teacher/educator/scholar matrix. IDEA Journal: Polyphonic voices, rainbow worlds: one destiny, v. 1, n. 1, p. 10, 1997. Tradução livre do autor em parceria com Geraldo Salvador de Araújo.

${ }^{4}$ Combs registra a seguinte relação de personagens e instituições: Winifred Ward / Northwestern University; Kenneth Graham / The University of Minnesota; Geraldine Silks / The University of Washington; Jed Davis / The University of Kansas (COMBS, 1997, p. 11).

${ }^{5}$ Mesmo correndo o risco de esquecer nomes importantíssimos para a história do Teatro-Educação nacional, cito os seguintes: Aladir Santos Lopes, Amicy Santos, Antonio Januzelli, Augusto Boal, Beatriz Ângela Vaz, B. de Paiva, Clóvis Garcia, Dilza Délia Dutra, Fanny Abramovitch, Flávio Império, Helena Barcelos, Hilton Carlos de Araújo, Ilo Krugli, Ingrid Dormien Koudela, Joana Lopes, Laís Aderne, Lúcia Benedetti, Luiza Barreto Leite, Luiz Paulo de Freitas, Maria Alice Vergueiro, Maria Clara Machado, Maria Lúcia Pupo, Paschoal Carlos Magno, Olga Reverbel, Santa Rosa, Yan Michalski, Yara Silveira e muitos outros (a relação foi elaborada, originalmente, por Marcos Bulhões).

${ }^{6}$ Nunes, B. Educação artística e filosofia da arte. Rio de Janeiro: MEC: FUNARTE, 1986. p. 3. 
O aprendizado cênico secularizou-se através do fazer e, sobretudo, fundamentado na instrução do mestre, procedimento que assegurou a existência de troupes e famílias de artistas, inclusive nos momentos em que o teatro era uma atividade proibida pelo poder instituído.

Na perspectiva da educação, Rousseau, Pestalozzi e Froebel observaram que o jogo proporcionado pelo teatro era um poderoso estímulo para o desenvolvimento da criança, sugerindo pistas para a investigação de pensadores como Dewey, Piaget e Wygotsky. Esse legado conceitual possibilitou aos educadores do presente século a formulação de idéias e métodos de ensino, calcados no movimento conhecido mundialmente por escola nova. Foram muitas as tendências teatrais representativas desse momento da pedagogia ocidental, destacando-se o play way, de Caldwell Cook; jogo dramático infantil, de Peter Slade; creative dramatics, de Winifred Ward e Brian Way; dança moderna educacional, de Rudolf Laban, Alan Garrard e Lise Ullman; linguagem criativa, de Marjorie Hourd; psicodrama, de Jacob Moreno.

Apesar dos avanços teóricos e metodológicos que vieram à tona com esses movimentos, predominou na escola uma visão espontaneísta que velava a essência da arte dando ênfase à livre-expressão, ao invés de instaurar experimentos geradores de saberes, práticas e fruição de obras. Educadores e artistas desfraldaram bandeiras alardeando a importância do processo educativo em detrimento do produto estético, seja nas escolas ou nos movimentos políticos de conscientização popular.

Era esse o pensamento praticado na escola brasileira quando a Educação Artística foi implantada, salvo raríssimas experiências isoladas. Nas aulas de Artes Cênicas, os professores limitavam-se a propor temas e distribuir material, deixando os alunos livres para improvisar à vontade. Somente aqueles mais tradicionais incorporavam o texto dramático, sendo muito comum a montagem de pecinhas em datas comemorativas. Nesse cenário, desenvolveu-se uma pseudoteoria que separava o que era arte do que poderia ser educação, mapeando em categorias estanques o teatro formal e o teatro educativo.

Durante anos de 1980, o quadro da Educação Artística polivalente - e, portanto, das Artes Cênicas - transfigurou-se aos poucos. Foram implantados cursos superiores em proporção geométrica, os professores tomaram as rédeas de sua própria história, ao tempo em que surgiram pesquisas sobre o Teatro na educação fundamental, dando início a uma profusão de idéias e práticas que hoje em dia vêm sendo avaliadas.

Além das experiências que se avolumaram no interior de escolas e instituições culturais, outros fatores contribuíram para esse salto qualitativo do Teatro-Educação, ressaltando-se os seguintes: i) o intercâmbio com o estrangeiro, seja através da divulgação de livros ou da vinda de especialistas renomados para ministrar cursos, participar de seminários e dar consultoria; ii) a larga difusão de obras como Improvisação para o teatro, de Viola Spolin, indicativa de caminhos para o ensino da linguagem cênica para crianças, adolescentes e adultos; iii) o surgimento tímido, mas eficiente de cursos de pós-graduação específicos em Arte, bem como a abertura de linhas de pesquisa sobre ensino de Teatro nos mestrados de áreas afins; iv) o agrupamento de profissionais em entidades para-acadêmicas, federações e sindicatos, o

\footnotetext{
7 O ideário dos movimentos de conscientização popular dos anos 60 - a exemplo dos CPCs da União Nacional dos Estudantes -UNE aproximava-se ao difundido pela escola nova e muitos deles baseavam-se no culto à livre-expressão, embora seu objetivo fosse a resistência cultural. Ver CANCLINI, 1998, p. 139-140.
} 
que propiciou a realização de simpósios regulares.

No bojo desse movimento, emergiram experiências de pessoas interessadas em contemporizar as idéias de Stanislavski, Brecht, Artaud, Grotowski, Barba e Peter Brook, dentre outros autores que referenciam a inovação metodológica contemporânea. Em meio a essas tendências, as mais relevantes privilegiam o jogo e a improvisação, e não se cercam, como no passado, de receios quanto ao uso do texto e à instrução enquanto regra didática. Considerando-se a diversidade de enfoques e procedimentos pedagógicos disseminados por escolas, instituições culturais, mestres e grupos teatrais, torna-se extremamente salutar o estudo dessas diferentes propostas, embora seja complicado analisar, sistematicamente, seus resultados ${ }^{8}$.

Com a configuração dos fenômenos anunciados até aqui, a discussão de práticas e a divulgação de pesquisas nas várias linguagens artísticas - marcas dos anos 90 -, percebe-se agora um cintilar alvissareiro no espaço do Teatro-Educação, muito embora, no plano prático da escolarização, tudo isso seja ainda uma incógnita.

$\mathrm{Na}$ grande maioria dos Estados brasileiros são raras as redes de ensino dotadas de professores devidamente preparados e, até mesmo nas escolas públicas das capitais, a realidade insiste em ofuscar o brilho das conquistas. Dentre os fatores que sobrevivem como fantasmas atormentando o ensino de Arte, sobressaem-se: turmas abarrotadas de alunos; espaço inadequado para a prática teatral; tempo insuficiente para preparação e desenvolvimento das aulas; má qualidade do material didático; diálogo truncado e falta de parcerias, mesmo entre docentes; inexistência ou descontinuidade no aperfeiçoamento profissional; mentalidade servil e avessa à ousadia; e baixa remuneração dos trabalhadores da educação.

Tendo em vista o enfrentamento dessas questões o poder público vem anunciando uma série de medidas, a exemplo dos Parâmetros Curriculares Nacionais - PCN. Essa estratégia representa uma novidade substantiva para a área da Arte, pois, pela primeira vez, o Ministério da Educação e Cultura - MEC presta orientação formal para o planejamento curricular da Música, das Artes Visuais, da Dança e do Teatro. Muito já se disse sobre o assunto e, pessoalmente, acho que os PCNs só deixarão de ser mais uma ação burocrática e prescritiva caso seja possível superar...

[...] a visão reducionista da escola, inserindo-se uma noção de currículo como tecido articulador no qual a formação de professores, as práticas pedagógicas e os processos de ensino, aprendizagem e avaliação se relacionem mutuamente. No momento, esses vínculos não existem?!

Fundamentando-se na Psicopedagogia e na Proposta Triangular, os PCNs não se limitam apenas a filosofar sobre os conceitos que sustentam as quatro áreas da disciplina Arte e a relacionar os respectivos objetivos e conteúdos; propõem também encaminhamentos didáticos e critérios de avaliação. A orientação metodológi-

\footnotetext{
${ }^{8}$ Ainda não existe no Brasil um estudo sistematizado sobre as metodologias praticadas no ensino do Teatro. A bibliografia estrangeira também não é muito extensa, excetuando-se trabalhos como o de SOMERs, J. Drama and theatre in education: contemporary research. Ontario: Captus University Publications, 1996.

9 SANTANA, A. N. P. Reconsiderando o ensino de artes cênicas. In: CONGRESSO NACIONAL DA FEDERAÇÃO DE ARTE EDUCADORES DO BRASIL, 11., 1998, Brasília. Anais... Brasília, DF: FAEB, 1998. p. 9-10.
} 
ca apresentada aos docentes sugere organização do espaço, do tempo, instrumentos de registro e documentação, como forma de organizar as atividades e as intervenções do professor junto ao aluno.

A ação de planejar um curso requer do educador uma atitude criadora, a seleção de conhecimentos e práticas que tornem possíveis descobertas e construção de saberes, desconsiderando o método enquanto modelo pronto. Essa é uma tarefa essencial ao ato de ensinar, pois "os encaminhamentos didáticos expressam a seriação dos conteúdos da área e as teorias da arte e da educação selecionadas pelo docente ${ }^{10 ”}$. Contudo, como este precisa conhecer referenciais e utilizá-los na prática pedagógica, é recomendável que se aproxime de experiências sistematizadas, teorias, pesquisas e, sobretudo, que participe de oficinas práticas no seu campo de saber ${ }^{11}$.

\section{Formação de professores e prática docente}

Para que as teorias e metodologias traduzam-se em avanços concretos na sala de aula, é essencial que se leve a sério a formação de professores. E, como as demais áreas que compõem o currículo, o Teatro precisa de profissionais com conhecimentos adequados para a tarefa da escolarização - não o professor faz de conta que atua improvisadamente e torna tudo superficial, nem tampouco o profissional deus ex machina que tudo sabe da linguagem artística e que, a cada situação, lança mão de seus poderes miraculosos. Num momento de crise na educação, faz-se necessário redirecionar a formação inicial e o aperfeiçoamento contínuo dos docentes, tendo em vista a grandeza da missão que cabe a esses profissionais.

A tarefa de preparar educadores é de toda a sociedade, cabendo às universidades e aos órgãos executores do ensino empreender ações objetivas, visando traduzir o estado do conhecimento que se tem acerca do assunto frente às perplexidades instauradas no processo da escolarização.

Pensando-se na sala de aula, não é mais possível conceber uma formação tradicionalmente dicotômica; não tem mais lugar também a abordagem polivalente que, por ser vazia de conteúdo, concebe um profissional cujo perfil assemelha-se à imagem pejorativa do pato - nada sem mergulhar, tem asas mas não voa e anda desengonçado. Na condição humana que se apresenta nesse fim de século, seria mais interessante considerar a metáfora sugerida por Leonardo Boff:

Cada um hospeda dentro de si uma águia. Sente-se portador de um projeto infinito. Quer romper os limites apertados de seu arranjo existencial. Há movimentos na política, na educação e no processo de mundialização que pretendem reduzir-nos a simples galinhas, confinadas aos limites do terreiro. Como vamos dar asas à águia,

\footnotetext{
${ }_{10}$ BRASIL. Ministério da Educação. Parâmetros curriculares nacionais da área de arte: I e II ciclos. Brasília, DF: 1997. p. 105.

${ }^{11}$ Refiro-me aqui ao trabalho de professores que construíram teorias a partir de suas práticas institucionais, a exemplo de Ingrid Dormien Koudela/USP e Helena Barcelos/UnB (in memorian), dentre outros. Refiro-me também a livros como os de Viola Spolin, especialmente Theatre game file (SPOLIN, Viola. Theatre game file. Evanston: Northwestern University Press, 1989), que detalham com precisão métodos de ensino em Teatro. Não existem muitas obras publicadas no Brasil a esse respeito - mesmo esta nunca foi traduzida -, embora um número considerável de relatórios de pesquisa, dissertações e teses comprovem a existência de boas referências.
} 
ganhar altura, integrar também a galinha e sermos heróis de nossa própria saga ${ }^{12}$ ? REFERÊNCIAS

BARBOSA, A. M. A imagem no ensino da arte. São Paulo: Perspectiva/Iochepe, 1991.

BARRET, G. Le spécialiste en théâtre éducation: une personnage étrange entre-deux. IDEA Journal: Polyphonic voices, rainbow worlds: one destiny, v. 1, n. 1, p. 6-8, 1997.

BOFF, L. A águia e a galinha: uma metáfora da condição humana. São Paulo: Vozes, 1997.

BRASIL. Ministério da Educação. Parâmetros curriculares nacionais da área de arte: I e II ciclos. Brasília, DF: 1997.

CANCLINI, N. G. Culturas híbridas: estratégias para entrar e sair da modernidade. São Paulo: EDUSP, 1998.

COLL, C. Psicologia e currículo: uma aproximação psicopedagógica à elaboração do currículo escolar. São Paulo: Ática, 1996.

COMBS, C. E. The drama/theatre/artist/teacher/educator/scholar matrix. IDEA Journal: Polyphonic voices, rainbow worlds: one destiny, v. 1, n. 1, p. 10-13, 1997.

NUNES, B. Educação artística e filosofia da arte. Rio de Janeiro: MEC: FUNARTE, 1986.

SANTANA, A. N. P. Reconsiderando o ensino de artes cênicas. In: CONGRESSO NACIONAL DA FEDERAÇÃO DE ARTE EDUCADORES DO BRASIL, 11., 1998, Brasília. Anais... Brasília, DF: FAEB, 1998.

SOMERS, J. Drama and theatre in education: contemporary research. Ontario: Captus University Publications, 1996.

SPOLIN, Viola. Theatre game file. Evanston: Northwestern University Press, 1989.

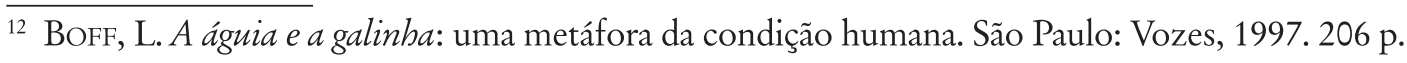

